\title{
The Prospect of a New Smart Healthcare System: A Wearable Device-Based Complex Structure of Position Detecting and Location Recognition System
}

\author{
Kyung Jin Chung ${ }^{1}$, Jayoung Kim ${ }^{1,2,3,4}$, Taeg-Keun Whangbo ${ }^{5}$, Khae-Hawn Kim ${ }^{1}$ \\ ${ }^{1}$ Department of Urology, Gil Medical Center, Gachon University College of Medicine and Science, Incheon, Korea \\ ${ }^{2}$ Departments of Surgery and Biomedical Sciences, Cedars-Sinai Medical Center, Los Angeles, CA, USA \\ ${ }^{3}$ Samuel Oschin Comprehensive Cancer Institute, Cedars-Sinai Medical Center, Los Angeles, CA, USA \\ ${ }^{4}$ University of California Los Angeles, Los Angeles, CA, USA \\ ${ }^{5}$ Department of Computer Science, Gachon University, Seongnam, Korea
}

In upcoming fourth industrial revolution era, it is inevitable to address smart healthcare as not only scientist but also clinician. We have the task to plan and realize this through human imagination, creativity, and applicability for the clarification of the direction of the development and utilization of this technology. One thing that is clear is that it is important to understand what information is needed, how to interpret it, what will be the outcomes, and how to respond in artificial intelligence and Internet of Things era. Therefore, we would like to briefly discuss the characteristics of smart healthcare, and, suggest one approach that is easily applicable in the current situation.

Keywords: Smart healthcare; Internet of Things; Wearable electronic devices; Urination

- Grant/Fund Support: This study was supported by a grant from the National Research Foundation of Korea (NRF-2017R1A2B2005412).

- Conflict of Interest: KHK, the corresponding author of this article, is an associate editor of International Neurourology Journal. However, he played no role whatsoever in the editorial evaluation of this article or the decision to publish it. Otherwise no potential conflict of interest relevant to this article was reported.

\section{OVERVIEW OF SMART HEALTHCARE}

Smart healthcare is the integration of high technology - such as artificial intelligence (AI), big data, Internet of Things (IoT), cloud, and Nano technology - with medical healthcare. Such integration can provide customized healthcare services without time and space limitations [1]. It is encouraging to look at a series of smart healthcare related studies - such as Dakurah et al. [2], Lee et al. [3], Kang et al. [4], and Myung et al. [5] - published in the International Neurourology Journal (INJ), a rising journal in the medical science field, dealing with such technology. In order to become a leader in this field, we believe that it is essential to address smart healthcare, and by adding our views on such technology, we wish to join this discussion.

The upcoming fourth industrial revolution will have an extensive and comprehensive impact, complexly affecting all areas of medicine. However, in reality, the direction of the development and utilization of technology in each area is not yet clear. There is still continuous development, therefore, planning and realization for the future must be done through human imagi-
Corresponding author: Khae-Hawn Kim (iD https://orcid.org/0000-0002-7045-8004 Department of Urology, Gil Medical Center, Gachon University College of Medicine and Science, 21 Namdong-daero 774beon-gil, Namdong-gu, Incheon 21565, Korea

E-mail: kimcho99@gilhospital.com / Tel: +82-32-460-3331 / Fax: +82-32-460-8340 Submitted: August 26, 2019 / Accepted after revision: September 11, 2019
This is an Open Access article distributed under the terms of the Creative Commons Attribution Non-Commercial License (http://creativecommons.org/licenses/by-nc/4.0/) which permits unrestricted non-commercial use, distribution, and reproduction in any medium, provided the original work is properly cited. 
nation, creativity, and applicability. One thing that is clear is that the future healthcare paradigm will change from the existing treatment-oriented healthcare to predictive, preventive, personalized, and participatory medicine; smart healthcare is at the center of this change [1].

$\mathrm{AI}$ and IoT are emerging as ways to address the surge in medical expenses due to the current rapidly aging population and the increase in chronic illnesses; they can lead to the transformation of the medical paradigm to one that is preventive and consumer-oriented through the daily management of individuals using various information and communication technology. IoT refers to objects and spatial networks that form intelligent relationships, such as sensing, networking, and information processing, without human intervention. In addition to information processing, it is also important to understand what information is needed, how to interpret it, what will be the outcomes, and how to respond. IoT and wearable devices are used for a relatively long period, and data collection and communication must be continuously performed in everyday life; therefore, they are increasingly moving to a general-purpose platform rather than a dedicated device or system [1]. As a result, connectivity and heterogeneity are thus important characteristics of smart healthcare. Connectivity includes interoperability and tightly coupled, bidirectional data communication over various types of networks. Heterogeneity refers to the use of various kinds of networks, sensors, actuators, and various extracted results from the same data.

\section{APPLICATION OF SMART HEALTHCARE}

We agree with the excellent viewpoints of Myung et al. [5] that emphasize the importance of research and development of small, diverse, accurate, and multifunctional sensors to accomplish preventative, early diagnostic, and patient-specific treatment. But development in this regard is required in a wide range of fields, and each field requires multidisciplinary development of biological, chemical, physical, physiologic, electrical, and nanoscience technologies. Furthermore, at the same time, breakthrough advancements in current medical science, such as conventional disease-related pathophysiology and treatment mechanism, should be accomplished. However, considering the extensiveness of the target area and limited affordable resources, research on certain disease-specific (or limited) technology is not easy to conduct. Clinical practitioners, who are currently treating patients directly and who simultaneously need to intro- duce smart healthcare in their clinics right away, should constantly study and discuss the available technologies and information that can be applied to patient care. In the current situation, it is necessary to make efforts toward development from the viewpoint of clinical application, such as increasing the applicability of technologies to medical treatment, improving the efficiency and effectiveness of medical treatment, enhancing the impact on human health, and contributing to the reduction of total medical expenses. As a part of such efforts, we have introduced the urination detection technology in INJ, which can be used to extract data according to human behavior patterns with a wearable device [6]. Our current clinical trial $(n=10)$, and interim analysis of smart medical devices for urinary diagnosis shows very interesting results. Human behavior patterns using wearable devices are very reliable and accurate. The overall diagnostic odds ratio compared to the 3-day urinary diary is 32.83 (95\% confidence interval [CI], 20.52-52.52). The pooled sensitivity and specificity are 0.82 (95\% CI, 0.74-0.87) and 0.88 (95\% CI, 0.86-0.90), respectively (Fig. 1). More detailed results will be presented in the future.

Internet of Small Things (IoST), an alternative concept to IoT, originated from the idea that it is not necessary to have a high-accuracy, large-volume data transmission technology when it comes to connecting all things to the internet [1]. The system of the low performance based IoST that actively detects and connects with the surrounding environment or situation is

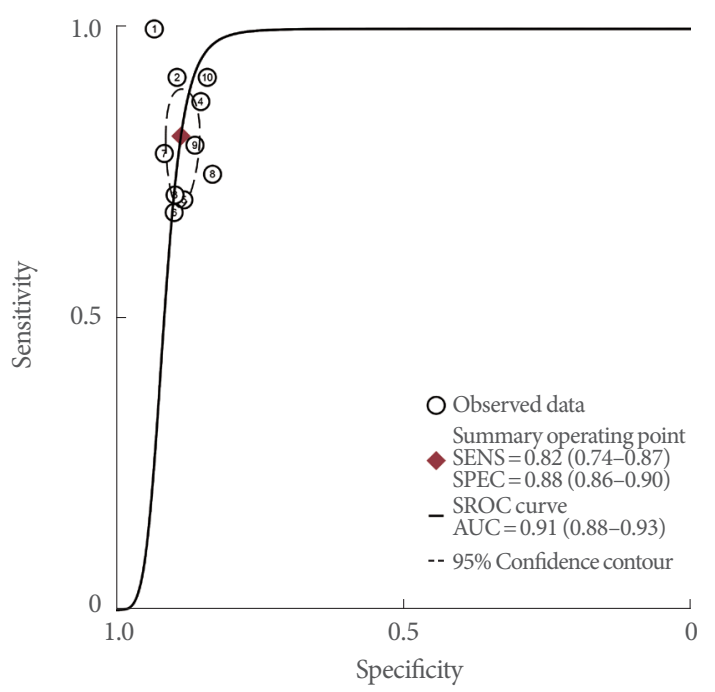

Fig. 1. Interim analysis of smart medical devices for urination detection. The overall sensitivity and specificity were presented $(n=10)$. SENS, sensitivity; SPEC, specificity; SROC, summary receiver operating characteristic; AUC, area under the curve. 
an attractive one because it provides various methods that can be applied to real-life in the early stages of the fourth industrial revolution, without the development of additional high-level technologies and with low cost.

\section{PROSPECT OF A NEW SMART HEALTHCARE SYSTEM}

For example, it is possible to provide various and complex services to users through only a combination of closed-position determination technology in residences and wearable network devices with several sensors such as motion, heartbeat, and oxygen saturation, etc. (like the current smart watch or smart band). Initially sensed information is collected and interpreted only within a closed system, and in case of detecting necessity of intervention on the closed structure, on an open network, or on interpretation from a combination of these two, the system will communicate with an external server. A schematic conceptual diagram of such a system is illustrated in Fig. 2. A multilayer system with a basic structure consisting of a closed small and simple sensor network can be developed, and data can be gathered and interpreted in the terminal connected with the network system. In this regard, we propose conducting an integrated research on a wearable device-based complex structure of closed-position detecting in residential and opened-location recognition system. Specifically, such a system would be an in- tegrated structure of a wearable long-distance network device with current motion sensors, biosensors, or alarm and a closedposition measuring location-based service system using a received signal strength indicator, such as a Zigbee network [7], which is a low-power wireless communication technology that can provide basic location information. This network is capable of not only monitoring one specific disease or substance but also providing diverse information about a wide variety of diseases, behaviors, and conditions, as well as suggesting directions for use, depending on what data is collected and interpreted. In this way, we can easily create a new concept related to healthcare by developing existing medical knowledge and various available technologies, and by developing and innovating the related algorithm accordingly. Moreover, the development of IoT, big data, and AI can be an important part of such innovation in smart healthcare, as they can provide significant help and opportunities for such innovation. Importantly, it can function well with the current technology and without high costs. Table 1 shows some examples of health-related data and services that can be derived from this system. Furthermore, it can be used in various medical fields and can be expanded to other fields in the future. To introduce such a system, new market value should be created through applying new ideas, needs should be discovered in the general lifestyle, and it should be implemented by communicating with the market.

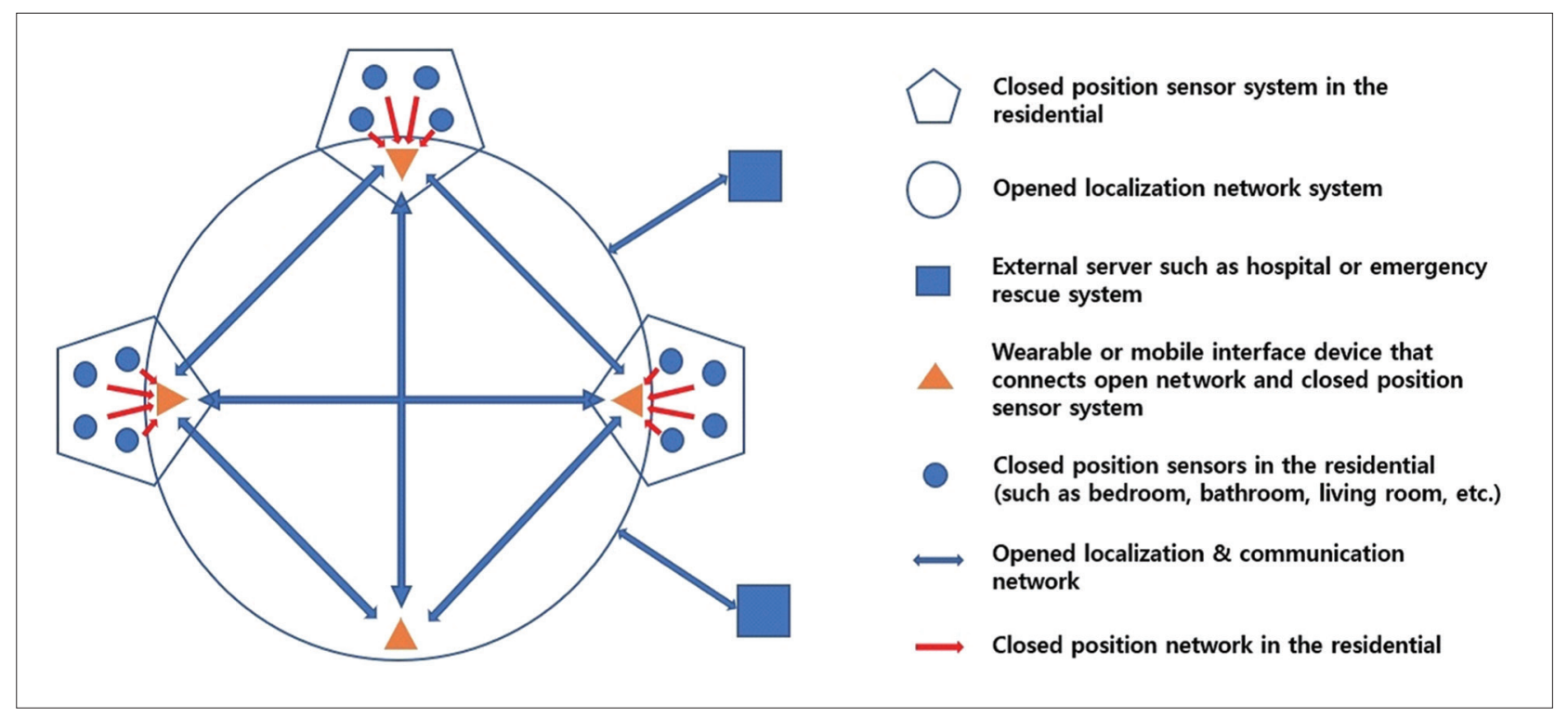

Fig. 2. A schematic conceptual diagram of Wearable Device-Based Complex Structure of Position Detecting and Location Recognition System. 
Table 1. Examples of health-related data and services that can be derived from the structure consisting of closed-position detecting in residential and opened-location recognition system

\begin{tabular}{|c|c|c|c|}
\hline Medical area & $\begin{array}{l}\text { Position detecting and } \\
\text { location recognition system }\end{array}$ & Behavior analysis & $\begin{array}{l}\text { Interpretation and } \\
\text { response }\end{array}$ \\
\hline Urology & $\begin{array}{l}\text { Movement to toilet Urination } \\
\text { behavior [6] }\end{array}$ & Urination behavior & $\begin{array}{l}\text { Urination time and frequency } \\
\text { LUTS (frequency, urgency, nocturia, } \\
\text { hesitancy) check }\end{array}$ \\
\hline Nephrology & Daily movement to toilet & Decreased urination behavior & Warning the possibility of ARF \\
\hline G-I movement & Daily movement to toilet & Exclude urination behavior & Detect defecation \\
\hline Dental & Located in basin and regular shaking & Brushing teeth & Regular dental care \\
\hline Auditory acuity & $\begin{array}{l}\text { Distance from the TV and checking } \\
\text { the loudness }\end{array}$ & & Possible noise induced deafness \\
\hline A sole resident & No movement for certain period & & $\begin{array}{l}\text { Warning of possible death of a lone } \\
\text { Emergency rescue }\end{array}$ \\
\hline Emergency medicine & Following stop in movement & Sudden change of height and impact & $\begin{array}{l}\text { Warning of fall-down and loss of } \\
\text { conscience } \\
\text { Emergency rescue }\end{array}$ \\
\hline Sleep science & $\begin{array}{l}\text { Fixation in bed according to daily } \\
\text { timeline } \\
\text { Check oxygen saturation }\end{array}$ & No or decreased movement & $\begin{array}{l}\text { Sleep time and pattern } \\
\text { Possibility of sleep apnea }\end{array}$ \\
\hline Lifestyle & $\begin{array}{l}\text { Frequent trips to the refrigerator } \\
\text { Daily movement } \\
\text { Detect daily life patterns such as sleep, } \\
\text { wake-up, urination, defecation, and } \\
\text { daily movement }\end{array}$ & Possible eating behavior & $\begin{array}{l}\text { Warning of overeating and obesity } \\
\text { Possibility of failed DM control } \\
\text { Lack of exercise and daily activity } \\
\text { Life adjustment }\end{array}$ \\
\hline Neurology & $\begin{array}{l}\text { Located in table and motion sensor } \\
\text { detect the degree of tremor }\end{array}$ & & $\begin{array}{l}\text { To determine the degree of Parkinson's } \\
\text { disease } \\
\text { To instruct to increase or decrease the } \\
\text { drug dose }\end{array}$ \\
\hline Rehabilitation & $\begin{array}{l}\text { Periodic fluctuation } \\
\text { Change of position }\end{array}$ & Check walk limping movement & Possibility of arthritis or injury \\
\hline \multirow[t]{3}{*}{ Psychiatry } & Decreased and slow movement & $\begin{array}{l}\text { Decreased change of position and } \\
\text { degree of momentum }\end{array}$ & Possibility of depression \\
\hline & Increased movement & $\begin{array}{l}\text { Increased change of position and } \\
\text { degree of momentum }\end{array}$ & Mood disorder, manic stage \\
\hline & $\begin{array}{l}\text { Accurate localization in conjunction with } \\
\text { surrounding networking among willing } \\
\text { patients and their family members }\end{array}$ & $\begin{array}{l}\text { Possibility of depression } \\
\text { If the patient located in rooftop } \\
\text { of building or on the bridge }\end{array}$ & $\begin{array}{l}\text { Warning of the possibility of suicide } \\
\text { (location checked on the rooftop of } \\
\text { the building) } \\
\text { Emergency rescue } \\
\text { Accurate location checked in dementia } \\
\text { patients } \\
\text { Emergency rescue }\end{array}$ \\
\hline
\end{tabular}

Various groups of patterns provide information about the lifestyle of the patient and the possibility of disease.

Including other sensors or a combination of algorithm, the number of detectable and interpretable items related to patients' health status can be increased.

LUTS, lower urinary tract symptoms; G-I, gastro-intestinal; ARF, acute renal failure; DM, diabetes mellitus. 


\section{ADDENDUM}

We completely agree with the opinion that development related to mobile health devices can be a game changer in smart healthcare and in the future healthcare industry [5]. For this to happen, the debate over the issue of invasion of privacy must be addressed and this problem should be resolved. The proposed system can be established with the help of consenting patients with the same disease or their families, and if those using the network agree to use it on a limited basis. Accordingly, this concept can be a solution for the fundamental weakness of IoT, that is, the issue of invasion of privacy. The controversy over invasion of privacy is one of the main obstacles to the development of a smart healthcare industry. It is crucial to make various possible efforts to eliminate the possession of personal information and stop human rights violations; however, at the same time, it is also important that the future smart healthcare is achieved through proper participatory consensus, and this consent of participants will be the first step toward the era of smart healthcare to resolve social regulation under this consensus.

\section{AUTHOR CONTRIBUTION STATEMENT}

- Full access to all the data in the study and takes responsibility for the integrity of the data and the accuracy of the data analysis: $\mathrm{KJC}, \mathrm{KHK}$

-Study concept and design: KJC

- Acquisition of data: KHK

- Analysis and interpretation of data: KHK

- Drafting of the manuscript: KJC

-Critical revision of the manuscript for important intellectual content: $T K W, J K$
- Statistical analysis: $K H K$

- Obtained funding: $K H K$

- Administrative, technical, or material support: $J K$

- Study supervision: $K H K$

\section{REFERENCES}

1. DACO Intelligence. Smart healthcare market and technology development trends and major corporate strategies: Facing the paradigm shift with the spread of Internet of Medicine (IoMT) [Internet]. Daco Intelligence; 2019 [cited 2019 Jul 25]. Available from: www.idaco.co.kr/default/product/product_01.php?idx=71\&mode=goods_ view\&topmenu=2\&left=1\&cate_code=CA100001 (Korean).

2. Dakurah MN, Koo C, Choi W, Joung YH. Implantable bladder sensors: a methodological review. Int Neurourol J 2015;19:133-41.

3. Lee M, Yoon Y, Ryu GH, Bok HS, Yoon K, Park S, et al. Innovative distribution priorities for the medical devices industry in the fourth industrial revolution. Int Neurourol J 2018;22(Suppl 2):S83-90.

4. Kang M, Park E, Cho BH, Lee KS. Recent patient health monitoring platforms incorporating internet of things-enabled smart devices. Int Neurourol J 2018;22:313.

5. Myung NV, Jung S, Kim J. Application of low-cost, easy-to-use, portable biosensor systems for diagnosing bladder dysfunctions. Int Neurourol J 2019;23:86-7.

6. Whangbo TK, Eun SJ, Jung EY, Park DK, Kim SJ, Kim CH, et al. Personalized urination activity recognition based on a recurrent neural network using smart band. Int Neurourol J 2018;22(Suppl 2):S91-100.

7. Tomar A. Introduction to ZigBee technology. Retrieved from (2011) [Internet]. Element14 the knode; c2009-2019 [cited 2019 Jul 30]. Available from: https://www.cs.odu.edu/ cs752/papers/zigbee-001.pdf. 